\title{
Dust Induced Atmospheric Absorption Improves Tropical Precipitations In Climate Models
}

\author{
YVES BALKANSKI ${ }^{1}$, RÉMY BONNET ${ }^{2}$, OLIVIER \\ BOUCHER $^{2}$, RAMIRO CHECA-GARCIA ${ }^{1}$ AND JÉRÔME \\ SERVONNAT ${ }^{1}$
}

${ }^{1}$ CEA-CNRS-UVSQ, IPSL

${ }^{2}$ Sorbonne Université-CNRS

Presenting Author: balkansk@1sce.ipsl.fr

One of the persistent bias in Earth System Models (ESMs) is that the position and the timing of the African monsoon are not well represented. These features of the monsoon are conditioned by the amount of heating received respectively by the Northern and the Southern Hemisphere. We show here how the shortwave radiation absorbed by dust plays a key role in positioning the monsoon in the IPSLCM6 ESM. We have developed a more accurate representation of dust absorption that is based on the observed dust mineralogical composition and accounts for very large particles. We analyze the results from two fully-coupled climate simulations of 100 years in terms of their simulated precipitation patterns against observations. Aerosol absorption induces more water vapor advection from the ocean to the Sahel, thereby providing an added supply of moisture available for precipitation. A striking benefit of the new dust optical and physical properties is that tropical precipitations over Sahel, tropical North Atlantic and West Indian Ocean are significantly improved compared to observations, without degrading precipitations elsewhere. We show that the improvement results from a thermodynamical and dynamical response to dust absorption is unrelated to natural variability. This work thus provides a path towards improving precipitation patterns in these regions by more realistically accounting for both physical and optical properties of the aerosol. 